\title{
Evaluation of the productivity of vertical oil wells by using different high shot density (HSD) guns
}

\begin{abstract}
This work explains how to evaluate the different perforation parameters of the production vertical oil wells by using well test reservoir description and perforation information. The necessary data have been collected from Hungarian oil wells including reservoir description data from the MOL Company files. Four vertical oil wells have been evaluated. The perforating guns data collected from the Schlumberger Company. Four perforating HSD guns were used with different charge and explosive load design.

In this study, calculation method used to determine the perforation depth, the influence of the different composite skin effect (damage skin factor, crushed zone skin factor, and the perforation skin factor), than we evaluate the flow rate of the different kind of guns. We consider the most important parameters influence the productivity of the perforated vertical oil wells. We obtained the relationship between the perforation depth and the skin factor, the perforation depth and the flow rate, the skin factor and the flow rate, and we identify the different flow rate. After giving the detailed figures and results, we evaluate the results of the perforation work.

In this work we proved that there is calculation method by which the flow rate of the vertical oil well can be estimated before the perforating. To have the best flow rate we should choose the right design of the perforation gun. Hungarian oil wells will improved their productivity by using high shut density guns. Flow rate evaluation needs a good knowledge of rock properties, and flow properties.
\end{abstract}

Volume 2 Issue 2 - 2017

\author{
Mahmoud O Elsharafi,' Tibor Bodi² \\ 'McCoy School of Engineering, Midwestern State University, \\ USA \\ 2Petroleum Engineering Department, University of Miskolc, \\ Hungary
}

Correspondence: Mahmoud O Elsharafi, McCoy School of Engineering, Midwestern State University, USA,

Email mahmoud.elsharafi@mwsu.edu

Received: February 21, 2017| Published: March 20, 2017

\section{Introduction}

Certainly, when a well has been cased and cemented a flow communication between the formations and wellbore must be provided, this contains creating a sequence of holes through casing and cement perforating. A lot of perforating guns are used in oil industry. Selecting the best perforation method is very important task during oil/gas well completion.

Skin Factor must be considered while perforating. The concept of skin factor initiates from Hurst work. ${ }^{1}$ They proposed skin factor as a means to quantify non-ideal flow. Van Everdinen's ${ }^{2}$ introduce the skin concept which includes two field examples that illustrate the use of skin to quantify formation damage and flow restriction due to perforation. These are the furthermost understandable causes of nearwellbore flow restriction.

The invading fluids and solids act together with the formation, creating a multitude of productivity damage effects, such as (emulsion blockage, water blockage, change in rock wet ability, hydration and swelling of formation clays, dispersion and migration of formation fines and grain cementation materials (clay particles), precipitation of inorganic salts (scaling), particle plugging of pores from entrained solids). The net effect of the invading fluid interaction with the formation is generally detrimental. The result is formation damage, causing additional pressure losses near the wellbore and a reduction in well productivity.

Regardless of the methods of damage prevention, there usually exists some degree of damage that must be considered in productivity calculations. The effect of formation damage on productivity has plagued the petroleum industry since its origin. It was treated systematically by Muskat, ${ }^{3}$ using a model of a well producing from a formation with two concentric annular regions of different permeability. He notes that the physical model of discontinuous radial difference in the permeability corresponds to a well which was initially drilled into homogeneous sand, the in homogeneity having been caused by a partial plugging or mudding off of the region immediately surrounding the sand face during the course of production or in the process of drilling.

Most wells today are completed with production casing cemented in place and perforated to allow reservoir fluids to enter the wellbore. The current perforating techniques use shaped charges to produce penetrating jets, which perforate through the casing and the cement sheath. Flow through perforations affects the productivity of a well primarily by changing the local flow geometry near the wellbore.

The effect of perforations on well performance is usually expressed as a skin factor. In fact, Muskat ${ }^{4}$ proposed the first appearance for perforation skin and discussed its similarity to an apparent wellbore radius. The specific geometrical parameters affecting the productivity of the perforated interval have been studied analytically by Muskat, ${ }^{4}$ with analogy models by McDowell \& Muskat $^{5}$ and Howard \& Watson, ${ }^{6}$ and with numerical simulators by Harris, ${ }^{7}$ Hong, ${ }^{8}$ \& Locke. ${ }^{9}$

The Harris ${ }^{7}$ study is one of the more comprehensive on the effect of perforation on productivity. Standing ${ }^{10}$ rearranged the Harris's results into two handy charts. That give skin as a function of perforation depth beyond the casing ( 0 to 30 in.), density (1,2, or 4 shots per foot), and phasing $\left(0^{\circ}\right.$ or $\left.180^{\circ}\right)$. Standing notes that the $180^{\circ}$ chart can also be used for $120^{\circ}$ phasing, and work by Locke suggests that the $180^{\circ}$ chart 
should also apply to $90^{\circ}$ phasing without much error. According to Locke, Harris's skin factors are too large for shallow penetration and too small for deep penetration, but the differences are small.

Harris's work does not consider the possibility that formation damage exists near the wellbore. Intuitively, penetration that exceeds the depth of the damage significantly improves the inflow. It is impossible, however, to estimate the magnitude and the extent of formation damage after the well has been cleaned up by acid factor. The Standing-Harris curves are specifically for one-halfinch perforations through cemented casing in $9 \frac{1}{2}$-in. Wellbore (bit diameter). Therefore, we consider the perforation damage in our calculation to determine the flow rate for different vertical oil wells in Hungary by using a different high shut density guns.

\section{Methodology of this work}

\section{High shot density (HSD) guns}

In this work, we assume those wells producing only single oil phase. Thus, in our calculation we calculated what would be the flow rate for the examined well if the choosing perforation guns were used for those wells. We looked through the Schlumberger engineering perforation systems for the power jet, and we tried to select the best one of those guns. Regarding to our theoretical overview for the perforation guns, we choose the four different kind of high shot density guns (HSD) as following:-

Gun designation 2 1/2 in HSD: Charge $31 \mathrm{~J} \mathrm{CS}$, HMX, Maximum Explosive Load 10.7 g, (API: Penetration 19.2 in, Entrance Hole 0.30 in).

Gun designation $27 / 8$ in HSD: Charge $34 \mathrm{~J} \mathrm{UJ}, \mathrm{HSD}$, Maximum Explosive Load 15.2 g, (API: Penetration 20.6 in, Entrance Hole 0.29 in).

Gun designation $27 / 8$ 7/8 in HSD: Charge $34 \mathrm{~J}$ UJ, HMX, Maximum Explosive Load 15.0 g, (API: Penetration 22.0 in, Entrance Hole 0.30 in).

Gun designation $27 / 8$ in HSD: Charge PJ 2906, HMX, Maximum Explosive Load 15.0 g, (API: Penetration 26.0 in, Entrance Hole 0.28 in).

\section{Skin factor and related concepts}

The constant and rate-dependent skins are discussed in this section. Generally, we are interested only in the pseudo steady-state skin and can neglect the transience of the skin effect. This also applies to the high-velocity skin. Expressed in equation, skin is included the calculation of total pressure drop and flow rate for pseudo steady-state conditions in an oil well as:

$$
q_{o}=\frac{k h\left(p_{R}-p_{w f}\right)}{141.2 \mu_{o} B_{o}\left[\ln \left(r_{e} / r_{w}\right)-0.75+s\right]}
$$

Where pressure drop due to skin is expressed as

$$
\Delta p_{s}=\frac{141.2 q_{o} \lambda_{o} B_{o}}{K h} S
$$

Skin $\mathrm{s}$ is the composite of all non-ideal conditions affecting flow, the most important of which are

$$
\mathrm{S}_{\mathrm{d}}=\text { formation-damage skin, }
$$

$\mathrm{S}_{\mathrm{c}}=$ completion skin due to partial penetration,

$\mathrm{S}_{\mathrm{p}}=$ perforation skin,

$\mathrm{S}_{\mathrm{b}}=$ blockage skin,

$\mathrm{S}_{\mathrm{G}}=$ gravel-pack skin,

$\mathrm{S}_{\mathrm{A}}=$ outer boundary geometry skin.

Craft \& Hawkins ${ }^{11}$ were the first to translate the Muskat model of a near-wellbore altered permeability into an expression for skin factor:

$$
S_{a}=\left(k / k_{a}-1\right) \ln \left(r_{a}-r_{w}\right)
$$

Where $\mathrm{k}$ is the formation permeability and $\mathrm{k}_{\mathrm{a}}$ is the altered permeability extending from the wellbore radius $r_{w}$ to a radius $r_{a}$. We select the subscript a denoting an altered permeability, rather than $d$ denoting formation damage, to emphasize that equation (3) is valid also for cases of increased near-wellbore permeability (stimulation). A problem Inherent with the practical use of equation (3) is that the altered zone is very difficult to quantify in terms of $\mathrm{k}_{\mathrm{a}}$ and $\mathrm{r}_{\mathrm{a}}$. That is, altered permeability and radius cannot be measured directly. At best, if the skin of the altered zone can be backed out of the total skin (calculated from well test analysis), an estimate of the radius of the altered zone $r_{a}$ allows calculation of the altered-zone permeability, by simple rearrangement of equation (3).

Other expressions relating the skin to altered-zone permeability and radius are obtained by simple rearrangement of equation (3):

$$
k_{a}=k\left[1+\frac{S_{a}}{\ln \left(r_{a} / r_{w}\right)}\right]^{-1}
$$

Solving for radius of the altered zone gives

$$
r_{a}=r_{w} \exp \left[1+\frac{S_{a}}{\left(\mathrm{k} / \mathrm{k}_{a}-1\right)}\right]
$$

Simplified expressions for the typical situation of a stimulated well when $\mathrm{k}_{\mathrm{a}}>\mathrm{k}$ are

$$
\begin{aligned}
& r_{a}=r_{w} \exp \left[-\mathrm{s}_{a]} \mathrm{k}_{\mathrm{a}}>>\mathrm{k}\right. \text { (stimulation) } \\
& s_{a}=r_{w}-\ln \left(r_{a} / r_{w}\right) \mathrm{k}_{\mathrm{a}}>>\mathrm{k} \text { (stimulation) }
\end{aligned}
$$

\section{Perforation penetration, geometry, and density}

The most important parameters recognized by the studies are:-

Penetration depth: The deeper the penetration, the better the performance.

Perforation diameter: The larger the diameter of the perforation tunnel, the better the flow performance.

Shot density: The more shots per foot, the better the performance.

Phasing: The phasing, the angular pattern of shots around the wellbore, has an effect on productivity.

Thompson ${ }^{12}$ has developed an empirical correlation relating perforation penetration to rock compressive strength. He gives a simple equation for estimating the correction from standard Berea penetration $\mathrm{L}_{\mathrm{pB}}$ to actual penetration $\mathrm{L}_{\mathrm{p}}$ (in): 
$L_{p}=\left\lfloor L_{p B} * 10^{3.7\left(10^{-5}\right)}\left(C_{B}-\mathrm{C}\right)\right\rfloor-\left(T_{s}+T_{c}\right)$

Where

$\mathrm{L}_{\mathrm{p}}=$ depth of penetration from the formation face (in.) (total core penetration=PTC)

$\mathrm{L}_{\mathrm{pB}}=$ depth of penetration from the inside of the casing, through a $3 / 8$-in. casing and $3 / 4$-in. cement sheath (in.) (total target penetration $=\mathrm{TTP}$ ),

$\mathrm{C}_{\mathrm{B}}=$ Berea compressive strength $\approx 6500$ Psia,

$\mathrm{C}=$ rock compressive strength $(\mathrm{Psia})$,

$\mathrm{Ts}=$ cement sheath thickness (in.) (usually $0.75 \mathrm{in}$.),

$\mathrm{Tc}=$ casing thickness (in.) (usually $0.375 \mathrm{in}$.).

Several authors ${ }^{9,13}$ suggest that the effect of a crushed zone can be quantified as a skin factor and included in IPR calculations. McLeod used a model of a "horizontal micro well" with formation damage around it as an analogy to a perforation surrounded by a crushed zone. His model gives the following relation for steady-state skin due to reduced crushed-zone permeability:

$$
S_{d p}=\left(\frac{k}{k_{d p}}-\frac{k}{k_{a}}\right)\left(\frac{12 h_{p}}{n_{L_{p}}}\right) \ln \left(r_{d p} / r_{p}\right)
$$

Where

$\mathrm{K}$ = formation permeability (md),

$\mathrm{k}_{\mathrm{dp}}=$ crushed-zone permeability near the wellbore (md),

$\mathrm{k}_{\mathrm{a}} \quad$ = damage-zone radius (in.),

$\mathrm{r}_{\mathrm{dp}}=$ crushed-zone radius (in.),

$r_{p}=$ perforation radius (in.),

$\mathrm{L}_{\mathrm{p}} \quad=$ depth of penetration (in.),

$\mathrm{h}_{\mathrm{p}}=$ perforated interval $(\mathrm{ft})$,

$\mathrm{n} \quad=$ total number of perforations.

\section{Composite skin factor}

Rowland, ${ }^{14}$ \& Jones \& Watts ${ }^{15}$ proposed simple models for adjusting individual skin factors for the effect of limited entry. In which flow convergence into the open interval is already completed before reaching the region where damage, high-velocity flow, blockage, and perforation effects become important. The higher local flow velocity magnifies the pressure drawdown caused by the other skin factors. Using the formal definition of skin factor and the $\mathrm{h} / \mathrm{hp}$ gain in local velocity (in relation to ideal flow), pressure drawdowns corresponds to the ideal flow and the various skins. So finally consideration the above mention, the total different pressure can be calculated by the following equation:-

$$
\Delta_{p t}=\frac{141.2 q_{o} \lambda_{o} B_{o}}{k h}\left[\ln \left(r_{e} / r_{w}\right)-0.75+S+D q_{o}\right]
$$

Where $\mathrm{S}$ is given by

$$
S=\mathrm{S}_{c}+S_{A}+S_{G}+S_{d p}+\left(h / h_{p}\right) \mathrm{S}_{p}+\left(h / h_{p}\right) S_{a}
$$

And $\mathrm{D}$ is given by

$$
D=D_{R}+D_{a}+D_{d p}+D_{G}
$$

Equation 11 and 12 are equally applicable to gas wells using pressure-squared, pressure, or pseudo-pressure. Note that $\mathrm{S}_{\mathrm{C}}, \mathrm{S}_{\mathrm{A}}, \mathrm{S}_{\mathrm{G}}$, and $S_{d p}$ are not corrected for limited entry. This is because limited entry is inherently considered when these skin factors are calculated individually. A similar condition holds for the individual elements D.

\section{Consider the perforation skin effect by karakas and tariq}

Karakas and Tariq (1988) have developed a procedure to calculate the skin effect due to perforations. This skin effect is a composite involving the plane-flow effect, $\mathrm{S}_{h}$, the vertical converging effect, $\mathrm{S}_{v}$, and the wellbore effect, $\mathrm{S}_{\mathrm{wb}}$, Hence

$$
s_{p}=s_{h}+s_{v}+s_{b}
$$

The pseudo skin factor, $\mathrm{S}_{\mathrm{h}}$, is given by

$$
s_{h}=\ln \frac{r_{w}}{r_{w}(\theta)}
$$

Where $r_{w}(\theta)$ is the effective wellbore radius and is function of the phasing angle $\theta$ :

$$
r_{w}{ }^{\prime}(\theta)=\left\{\begin{array}{l}
l_{p} / 4 \\
\alpha \theta\left(r_{w}+l_{p}\right)
\end{array}\right\} \text { When } \theta \neq 0
$$

Where $l_{p}$ is the length of the perforation and $\alpha \theta$ is a phase dependent variable and can be obtained from Table 1 .

Table I Depending of $\alpha \theta$ on Phasing

\begin{tabular}{ll}
\hline Perforation phasing & $\alpha \theta$ \\
\hline $0^{\circ}\left(360^{\circ}\right)$ & 0.25 \\
$180^{\circ}$ & 0.5 \\
$120^{\circ}$ & 0.648 \\
$90^{\circ}$ & 0.726 \\
$60^{\circ}$ & 0.813 \\
$45^{\circ}$ & 0.86
\end{tabular}

The vertical pseudo skin factor, $\mathrm{S}_{\mathrm{V}}$, Can be calculated after certain dimensionless variables are determined:

$$
h_{D}=\frac{h}{l_{p}} \sqrt{\frac{k_{h}}{k_{v}}}
$$

Where $\mathrm{h}$ is the distance between perforations and is exactly inversely proportional to the shot density $k_{h}$ and $k_{v}$ is the horizontal and vertical permeability's respectively;

$$
r_{p d}=\frac{r_{\text {perf }}}{2 h}\left(1+\sqrt{\frac{k_{v}}{k_{h}}}\right)
$$

Where $r_{p e r f}$ is the perforation diameter, and

$$
r_{w d}=\frac{r_{w}}{l_{p}+r_{w}}
$$


The vertical pseudo skin effect is then given by

$$
S_{v}=10^{a} h_{D}^{b-1} \mathrm{r}_{p D}{ }^{b}
$$

Where $\mathrm{a}$ and $\mathrm{b}$ are given by

$$
\begin{aligned}
& a=a_{1} \log r_{p D}+a_{2} \\
& b=b_{1}+r_{p D}+b_{2}
\end{aligned}
$$

The values of the constants $a_{1}, a_{2}, b_{1}$, and $b_{2}$, are given in Table 2 as functions of the phasing angle, $\theta$.

Table 2 Vertical Skin Correlation Coefficients

\begin{tabular}{lllll}
\hline Phasing & $\mathbf{a}_{1}$ & $\mathbf{a}_{2}$ & $\mathbf{b}_{1}$ & $\mathbf{b}_{2}$ \\
\hline $0^{\circ}\left(360^{\circ}\right)$ & -2.091 & 0.0453 & 5.1313 & 1.8672 \\
$180^{\circ}$ & -2.025 & 0.0943 & 3.0373 & 1.8115 \\
$120^{\circ}$ & -2.018 & 0.0634 & 1.6136 & 1.777 \\
$90^{\circ}$ & -1.905 & 0.1038 & 1.5674 & 1.6935 \\
$60^{\circ}$ & -1.898 & 0.1023 & 1.3654 & 1.649 \\
$45^{\circ}$ & -1.788 & 0.2398 & 1.1915 & 1.6392 \\
\hline
\end{tabular}

Finally, the wellbore skin effect, $\mathrm{s}_{\mathrm{wb}}$, can be approximated by

$S_{w b}=C_{1} e^{c_{2} r^{r} w}$

The constants $\mathrm{c}_{1}$ and $\mathrm{c}_{2}$ can be obtained from Table 3

Table 3 Variables $C_{1}$ and $C_{2}$.

\begin{tabular}{lll}
\hline Perforation phasing & $C_{1}$ & $C_{2}$ \\
\hline $0^{\circ}\left(360^{\circ}\right)$ & $1.60 \mathrm{E}-01$ & 2.675 \\
$180^{\circ}$ & $2.60 \mathrm{E}-02$ & 4.532 \\
$120^{\circ}$ & $6.60 \mathrm{E}-03$ & 5.42 \\
$90^{\circ}$ & $1.90 \mathrm{E}-03$ & 6.155 \\
$60^{\circ}$ & $3.00 \mathrm{E}-04$ & 7.509 \\
$45^{\circ}$ & $4.60 \mathrm{E}-05$ & 8.791 \\
\hline
\end{tabular}

\section{General data of the wells}

We collected twelve wells data from the MOL Oil Company in Hungary and we choose four of them to study in this work. For those wells, we collected a well test evaluation report which was including some of the parameters which was necessary such as a reservoir description and fluid properties as well as the layer properties. The data which we used in the calculation model is shown in (Table 4-7). We made assumption in some of the data which wasn't including in the well test data and the perforation information. We couldn't get the perforation data from the MOL Oil Company. We made our assumption to many parameters depending on the Hungarian oil vertical well situation. We used some information from the Schlumberger design report. We assumed that the damage zone permeability equal to the formation oil permeability divided by five. The vertical permeability it usually equal to the damage zone permeability, and the horizontal permeability it is usually equal to the oil permeability. Our assumption were for some parameters such as (Radiuses of formation damage, Horizontal permeability, Vertical permeability, Damaged zone permeability, Crushed zone permeability, Crushed zone thickness). (Table 4-7) show the data for the well parameters matching of wells $1,2,3$, and 4 including the reservoir description and the perforation

\begin{tabular}{|c|c|}
\hline Parameters & Values \\
\hline Formation thickness (ft) & 26.2467 \\
\hline Reservoir pressure (psia) & 2246.18 \\
\hline Flow Bottom hole pressure (psia) & 2185.933 \\
\hline Oil viscosity (cp) & 0.27377 \\
\hline Oil formation volume factor (bbl/STB) & $1.37|5|$ \\
\hline Reservoir permeability $(\mathrm{mD})$ & 169 \\
\hline Well radius $(\mathrm{ft})$ & 0.292 \\
\hline Drainage radius ft) & 4969.245 \\
\hline Average Formation Porosity & 0.3 \\
\hline Perforation interval (ft) & 6.56 \\
\hline Rock compressive strength (calculated, psia) & $4 \mid 25.548$ \\
\hline $\begin{array}{l}\text { Perforation tunnel diameter for the different guns } \\
(1,2,3,4) \text { (in) }\end{array}$ & $0.30,0.29,0.30,0.28$ \\
\hline Perforation phasing,$\left(^{\circ}\right)$ & 60 \\
\hline Shot density (shots/ft) & 6 \\
\hline Crushed zone thickness (assumed, in) & 0.5 \\
\hline Crushed zone permeability (assumed, mD) & 5 \\
\hline Damaged zone permeability (assumed k/5, mD) & 33.8 \\
\hline Vertical permeability (equal ka, mD) & 33.8 \\
\hline Horezontal permeability (equal k,mD) & 169 \\
\hline Radiused of formation damage (assumed ,ft) & 1.375 \\
\hline Formation Temperature (deg F) & 206.599 \\
\hline
\end{tabular}
information, respectively.

Table 4 The Basic Data for Well I 
Table 5 The Basic Data for Well 2

\begin{tabular}{ll}
\hline Parameters & Values \\
\hline Formation thickness (ft) & 19.685 \\
Reservoir pressure (psia) & 2347.91 \\
Flow Bottom hole pressure (psia) & 2322.513 \\
Oil viscosity (cp) & 0.67184 \\
Oil formation volume factor (bbl/STB) & 1.25527 \\
Reservoir permeability (mD) & 214 \\
Well radius (ft) & 0.292 \\
Drainage radius (ft) & 4336.16 \\
Average Formation Porosity & 0.32 \\
Perforation interval (ft) & 3.28 \\
Rock compressive strength (calculated, psia) & 4094.174 \\
Perforation tunnel diameter for the different guns & $0.30,0.29,0.30,0.28$ \\
(I,2,3,4) (in) & 60 \\
Perforation phasing , ${ }^{\circ}$ ) & 6 \\
Shot density (shots/ft) & 1.375 \\
Crushed zone thickness (assumed, in) & 0.5 \\
Crushed zone permeability (assumed, $\mathrm{mD}$ ) & 5 \\
Damaged zone permeability (assumed k/5, mD) & 42.8 \\
Vertical permeability (equal ka, mD) & 42.8 \\
Horezontal permeability (equal k,mD) & 214 \\
Radiused of formation damage (assumed ,ft) & 194.319 \\
Formation Temperature(deg F) & \\
\hline
\end{tabular}

Table 6 The Basic Data for Well 3

\begin{tabular}{ll}
\hline Parameters & Values \\
\hline Formation thickness (ft) & 4.9213 \\
Reservoir pressure (psia) & 2270.691 \\
Flow Bottom hole pressure (psia) & 2226.469 \\
Oil viscosity (cp) & 0.28194 \\
Oil formation volume factor (bbl/STB) & 1.37042 \\
Reservoir permeability (mD) & 243 \\
Well radius (ft) & 0.292 \\
Drainage radius (ft) & 4641.2 \\
Average Formation Porosity & 0.25 \\
Perforation interval (ft) & 4.92 \\
Rock compressive strength (calculated, psia) & 4217.39 \\
Perforation tunnel diameter for the different & $0.30,0.29,0.30,0.28$ \\
guns (I,2,3,4) (in) & 60 \\
Perforation phasing , $\left({ }^{\circ}\right.$ ) & 6 \\
Shot density (shots/ft) & \\
\hline
\end{tabular}

Table Continued....

\begin{tabular}{ll} 
Parameters & Values \\
\hline Crushed zone thickness (assumed, in) & 0.5 \\
Crushed zone permeability (assumed, mD) & 5 \\
Damaged zone permeability (assumed k/5, mD) & 48.6 \\
Vertical permeability (equal ka, mD) & 48.6 \\
Horezontal permeability (equal k,mD) & 243 \\
Radiused of formation damage (assumed ,ft) & 1.375 \\
Formation Temperature (deg F) & 201.469
\end{tabular}

Table 7 The Basic Data for Well 4

\begin{tabular}{ll}
\hline Parameters & Values \\
\hline Formation thickness (ft) & 193.57 \\
Reservoir pressure (psia) & 2112.895 \\
Flow Bottom hole pressure (psia) & 2075.546 \\
Oil viscosity (cp) & 0.39349 \\
Oil formation volume factor (bbl/STB) & 1.6428 \\
Reservoir permeability (mD) & 301 \\
Well radius (ft) & 0.187 \\
Drainage radius (ft) & 1705.6 \\
Average Formation Porosity & 0.07 \\
Perforation interval (ft) & 32.8 \\
Rock compressive strength (calculated, psia) & 4101.885 \\
Perforation tunnel diameter for the different & $0.30,0.29,0.30,0.28$ \\
guns (I,2,3,4) (in) & 60 \\
Perforation phasing , ( ${ }^{\circ}$ ) & 6 \\
Shot density (shots/ft) & 1.375 \\
Crushed zone thickness (assumed, in) & 0.5 \\
Crushed zone permeability (assumed, mD) & 5 \\
Damaged zone permeability (assumed k/5, mD) & 60.2 \\
Vertical permeability (equal ka, mD) & 60.2 \\
Horezontal permeability (equal k,mD) & 301 \\
Radiused of formation damage (assumed ,ft) & 210.559 \\
Formation Temperature(deg F) & \\
\hline
\end{tabular}

\section{Results and discussion}

Equation (1) was used to calculate the flow rate. Thomson method was used to calculate the perforation depth by using equation (8). To calculate the perforation depth, it was necessary to know the formation compressive strength. To calculation flow rate, we need to calculate the composite skin factor considering the equations number $(3,9,11$, and 13). We consider the effect of different parameters such as (damage zone skin factor, perforation skin factor, and crushed zone skin factor). We showed the calculation of perforation skin factor, the calculation of the damage zone skin factor, and the calculation of the crushed zone skin factor. In our calculation we neglected the value of the other parameters skin such the completion skin due to the 
partial penetration $\left(\mathrm{S}_{\mathrm{C}}\right)$, and the outer boundary geometry skin $\left(\mathrm{S}_{\mathrm{A}}\right)$, as well the gravel-pack skin $\left(\mathrm{S}_{\mathrm{G}}\right)$ because our work was considering on the effect of the perforation skin. In our work we calculate the perforation skin effect by using Karakas and Tariq method because the other methods were not including all the phasing angles. To calculate the perforation skin effect by using Karakas and Tariq method, we consider the equations number $(13,14,15,16,17,18,19,20,21$, and 22). In our work we made calculation steps as following:

I. Calculation the penetration depth.

II. Calculation the Perforation Skin Effect by using Karakas and Tariq method.

III. Calculation the effect of a crushed zone skin factor

IV. Calculation the composite skin factor.

V. Calculation the flow rate.

In this work, we calculated the perforation damage zone skin factor using the equation number (3) considering the damage zone permeability and damage zone radius; first we calculated all parameters of the well number 1 to get the flow rate.

\section{Calculate the penetration depth $\left(L_{p}\right)$}

To calculate the penetration depth we must know the compressive strength of the formation oil well. We used Thompson correlation (eq 8) to calculate the penetration depth, and the data from the (Table 4) (Table 8). We have to determine the effective compressive strength which is equal to the overburden pressure minus the formation pressure. The overburden can be estimated by multiplying depth by the overburden gradient of $1.1 \mathrm{psi} / \mathrm{ft}$. the formation pressure is the reservoir pressure at the time of perforating.

Table 8 Required Data to Calculate the Compressive Strength

\begin{tabular}{ll}
\hline Data & Value \\
\hline Berea compressive strength (CB) & 6500 psia \\
Perforation Depth interval & From 5789.2 to 5795.76 \\
Cement sheath thickness (TS) & Usually 0.75 in \\
Casing thickness (TC) & Usually 0.375 in \\
\hline
\end{tabular}

The overburden pressure $=[1.1 \mathrm{psi} / \mathrm{ft} *$ (average perforation depth $\mathrm{ft})]$.

Average perforation depth $\mathrm{ft} .=((5789.2+5795.76) / 2) \mathrm{ft}$

Compressive strength $\mathrm{psiz}=[1.1 \mathrm{psi} / \mathrm{ft} *$ (average perforation depth $\mathrm{ft}$ )-(the formation pressure psia)]. Table 9 shows the calculation results of perforation depth.

Table 9 The Results of Perforation Depth Calculation for Well I

\begin{tabular}{llllll}
\hline Number of gun & Phasing & Shots (spf) & $\begin{array}{l}\text { Compressive } \\
\text { strength ( Pisa) }\end{array}$ & Total target penetration (in) & $\begin{array}{l}\text { Perforation depth } \\
\text { ( in ) }\end{array}$ \\
\hline ( $)$ & 60 & 6 & 4125.548 & 19.2 & 22.425 \\
2 & 60 & 6 & 4125.548 & 20.6 & 24.142 \\
3 & 60 & 6 & $4 \mid 25.548$ & 22 & 25.859 \\
4 & 60 & 6 & $4 \mid 25.548$ & 26 & 30.765 \\
\hline
\end{tabular}

\section{Calculate the perforation skin effect by using karakas and tariq method}

We choose this method instead of the other methods because in this method we can calculate the perforation skin factor of the phasing angle $60^{\circ}$ and 6 shots per feet.

Table 10 Calculation Results of the Flow Pseudo Skin Factor $\left(\mathrm{S}_{h}\right)$ for Well I

\section{Calculation of the flow pseudo skin factor $\left(S_{h}\right)$}

We used equation (14) to calculate $\left(\mathrm{S}_{\mathrm{h}}\right)$. We calculated the effective wellbore radius as function of the phasing angle $\left(60^{\circ}\right)$ from the equation (15). We used table 1 to determine a phase dependent variable $(\alpha \theta)$. Table 10 shows the calculation results of the flow pseudo skin factor $\left(\mathrm{S}_{\mathrm{h}}\right)$.

\begin{tabular}{llllllll}
\hline No & Phasing $\left({ }^{\circ}\right)$ & Shots (spf) & $\mathbf{r}_{w}(\mathrm{ft})$ & $\mathbf{L}_{\mathrm{p}}(\mathrm{in})$ & $\boldsymbol{\alpha} \boldsymbol{\theta}$ & $\mathbf{r}_{\mathrm{w}}(\boldsymbol{\theta})$ & $\mathbf{S}_{\mathrm{h}}$ \\
\hline $\mathrm{I}$ & 60 & 6 & 0.292 & 22.425 & 0.813 & 18.468 & -4.147 \\
2 & 60 & 6 & 0.292 & 24.142 & 0.813 & 19.865 & -4.219 \\
3 & 60 & 6 & 0.292 & 25.859 & 0.813 & 21.26 & -4.287 \\
4 & 60 & 6 & 0.292 & 30.765 & 0.813 & 25.249 & -4.459
\end{tabular}

\section{Calculate the vertical pseudo skin factor $\left(\mathbf{S}_{\mathrm{v}}\right)$}

We used equation (19) to calculate $\left(\mathrm{S}_{\mathrm{v}}\right)$. To calculate $\left(\mathrm{S}_{\mathrm{v}}\right)$ we must calculated certain dimensionless variables. We Calculated $\left(h_{D}\right)$ by using equation 16 . We Calculated $\left(\mathrm{r}_{\mathrm{pD}}\right)$ by using equation (17). We Calculated the values $\mathrm{a}, \mathrm{b}$, by using equations 20 , and 21 . The constants values $a_{1}, b_{1}$ are given in the Table 2 as function of the phasing angle $\left(60^{\circ}\right)$. By using all the parameters that we calculated in the different shapes, we can determine the vertical pseudo skin effect $\left(\mathrm{S}_{\mathrm{v}}\right)$. Table 11-14 shows calculation results of the vertical pseudo skin factor $\left(\mathrm{S}_{\mathrm{v}}\right)$. 
Table I I Calculation Results of the Dimensionless Variable $\left(h_{D}\right)$ for Well I

\begin{tabular}{lllllll}
\hline No & Phasing $\left(^{\circ}\right)$ & Shots $(\mathbf{s p f})$ & $\mathbf{h}(\mathbf{f t})$ & $\mathbf{L}_{\mathrm{p}}(\mathrm{in})$ & $\mathbf{k}_{\mathrm{h}} / \mathbf{k}_{\mathrm{v}}$ & $\mathbf{h}_{\mathrm{D}}$ \\
\hline 1 & 60 & 6 & 0.167 & 22.425 & 5 & 0.016 \\
2 & 60 & 6 & 0.167 & 24.142 & 5 & 0.015 \\
3 & 60 & 6 & 0.167 & 25.859 & 5 & 0.014 \\
4 & 60 & 6 & 0.167 & 30.765 & 5 & 0.012 \\
\hline
\end{tabular}

Table I 2 Calculation Results of the Dimensionless Variable $\left(r_{p D}\right)$ for Well I

\begin{tabular}{lllllll}
\hline No & Phasing $\left({ }^{\circ}\right)$ & Shots (spf) & $\mathbf{L}_{\mathrm{p}}$ (in) & $\mathbf{k}_{\mathrm{h}} / \mathbf{k}_{\mathrm{v}}$ & $\mathbf{r}_{\text {perf }}$ (in) & $\mathbf{r}_{\mathbf{p}} \mathbf{D}$ \\
\hline $\mathrm{I}$ & 60 & 6 & 22,425 & 0.2 & 0.3 & 0.036 \\
2 & 60 & 6 & 24,142 & 0.2 & 0.29 & 0.035 \\
3 & 60 & 6 & 25,859 & 0.2 & 0.3 & 0.036 \\
4 & 60 & 6 & 30,765 & 0.2 & 0.28 & 0.034 \\
\hline
\end{tabular}

Table I 3 Calculation Results of the Constants $a$ and $b$ for Well I

\begin{tabular}{lllll}
\hline No & Phasing $\left({ }^{\circ}\right)$ & Shots (spf) & a & b \\
\hline 1 & 60 & 6 & 1.629 & 3.05 \\
2 & 60 & 6 & 1.636 & 3.049 \\
3 & 60 & 6 & 1.629 & 3.05 \\
4 & 60 & 6 & 1.644 & 3.048
\end{tabular}

Table I 4 Calculation Results of the Vertical Pseudo Skin Factor $\left(\mathrm{S}_{\mathrm{v}}\right)$ for Well I

\begin{tabular}{llll}
\hline No & Phasing $\left(^{\circ}\right)$ & Shots(spf) & $\left(\mathbf{S}_{\mathrm{v}}\right)$ \\
\hline 1 & 60 & 6 & $3.84 \mathrm{E}-04$ \\
2 & 60 & 6 & $3.05 \mathrm{E}-04$ \\
3 & 60 & 6 & $2.86 \mathrm{E}-04$ \\
4 & 60 & 6 & $1.7 \mathrm{IE}-04$
\end{tabular}

\section{Calculate the wellbore skin factor $\left(\mathbf{S}_{\mathrm{wb}}\right)$}

$\mathrm{S}_{\mathrm{wb}}$ can be determined by using equation (22), and the constants $\mathrm{c}_{1}, \mathrm{c}_{2}$ can be obtained from Table 3 , the value $\left(\mathrm{r}_{\mathrm{wD}}\right)$ from the equation (18). Finally we can determine the perforation skin effect $\left(\mathrm{S}_{\mathrm{p}}\right)$ by using the equation (13). Table 15 calculation results of the wellbore skin factor $\left(\mathrm{S}_{\mathrm{wb}}\right)$ and Table 16 shows the calculation results of the perforation skin effect $\left(\mathrm{S}_{\mathrm{P}}\right)$.

Table 15 Calculation Results of the Wellbore Skin Factor $\left(S_{w b}\right)$ for Well I

\begin{tabular}{lllllll}
\hline No & Phasing( $\left(^{\circ}\right)$ & Shots(spf) & $\mathbf{r}_{w}(\mathbf{f t})$ & $\mathbf{L}_{\mathrm{p}}(\mathrm{in})$ & $\mathbf{r}_{\mathrm{wD}}$ & $\mathbf{S}_{\mathrm{wb}}$ \\
\hline $\mathrm{I}$ & 60 & 6 & 0.292 & 22.425 & 0.013 & 0.000375 \\
2 & 60 & 6 & 0.292 & 24.142 & 0.012 & 0.000369 \\
3 & 60 & 6 & 0.292 & 25.859 & 0.011 & 0.000364 \\
4 & 60 & 6 & 0.292 & 30.765 & 0.009 & 0.000353
\end{tabular}

Table 16 Calculation Results of the Perforation Skin Effect $\left(S_{p}\right)$ for Well I

\begin{tabular}{lllllll}
\hline No & Phasing $\left(^{\circ}\right)$ & Shots(spf) & $\mathbf{S}_{h}$ & $\mathbf{S}_{\mathrm{v}}$ & $\mathbf{S}_{\mathrm{wb}}$ & $\mathbf{S P}$ \\
\hline $\mathrm{I}$ & 60 & 6 & -4.147 & $3.83 \mathrm{E}-07$ & 0.000375 & -4.146 \\
2 & 60 & 6 & -4.219 & $3.05 \mathrm{E}-07$ & 0.000369 & -4.219 \\
3 & 60 & 6 & -4.287 & $2.86 \mathrm{E}-07$ & 0.000364 & -4.287 \\
4 & 60 & 6 & -4.459 & $1.7 \mathrm{IE}-07$ & 0.000353 & -4.459
\end{tabular}

\section{Calculate the effect of a crushed zone skin factor $\left(S_{d p}\right)$}

By using the equation (9) and the data in in Table 4 we can determine $\left(\mathrm{S}_{\mathrm{dp}}\right)$. We determine the following:

Total number of perforation $(\mathrm{N})=$ Shots $(\mathrm{spf}) *$ Perforation interval $\left(h_{p}\right)$ ft. $N=6 * 6.56=39.36$ shots.

Perforation radius $\left(r_{p}\right)$ and the Crushed zone radius $\left(r_{d p}\right)$ are given from the Table 17 . We assumed that the $\mathrm{k}=\mathrm{k} / 5$ that usually in Hungarian oil well. Table 18 shows the Calculation Results of crushed zone skin factor (Sdp). Table 18 shows the calculation results of crushed zone skin factor (Sdp).
Table 17 Show the Perforation Radius $\left(r_{p}\right)$ and the Crushed Zone Radius $\left(r_{d p}\right)$ for Well I

\begin{tabular}{lll}
\hline No & Perforation radius (In) & Crushed zone radius(In) \\
\hline 1 & 0.15 & 0.65 \\
2 & 0.145 & 0.645 \\
3 & 0.15 & 0.65 \\
4 & 0.14 & 0.64 \\
\hline
\end{tabular}


Table I 8 The Calculation Results of Crushed Zone Skin Factor $\left(\mathrm{S}_{\mathrm{dp}}\right)$ for Well I

\begin{tabular}{llllllllll}
\hline No & $\mathbf{k}_{\mathrm{o}}(\mathbf{m D})$ & $\mathbf{k}_{\mathrm{a}}(\mathbf{m D})$ & $\mathbf{r}_{\mathrm{a}}(\mathbf{f t})$ & $\mathbf{r}_{\mathrm{w}}(\mathbf{f t})$ & $\mathbf{k}_{\mathrm{dp}}(\mathbf{m D})$ & $\mathbf{h}_{\mathrm{p}}(\mathrm{in})$ & $\mathbf{L}_{\mathrm{p}}(\mathrm{in})$ & $\mathbf{S}_{\mathrm{p}}$ & $\mathbf{S}_{\mathrm{dp}}$ \\
\hline $\mathrm{I}$ & 169 & 33.8 & 1.375 & 0.292 & 5 & 6.56 & 22.4247 & -4.1467 & 3.766428 \\
2 & 169 & 33.8 & 1.375 & 0.292 & 5 & 6.56 & 24.14187 & -4.21958 & 3.56099 \\
3 & 169 & 33.8 & 1.375 & 0.292 & 5 & 6.56 & 25.85903 & -4.2875 & 3.266209 \\
4 & 169 & 33.8 & 1.375 & 0.292 & 5 & 6.56 & 30.76522 & -4.45946 & 2.845485 \\
\hline
\end{tabular}

\section{Calculate the composite skin factor (S)}

We used equation (11) to determined (S). In our calculation we considered the effect of the perforation skin factor, and the crushed zone skin factor, thus we calculate the damage zone skin factor. In our calculation we suggest that the completion skin factor is equal zero, but if we consider the value of the completion skin factor like (10), we will have the lower flow rate. We calculated the value of the damaged zone skin factor from the equation (3), thus we used the data in the Table 4. Table 19 shows the calculation results of the skin factor (S).
Figure 1 shows the relationship between the perforation depth and the skin factor, considering the theoretical overview as you can see in the figure and this is favorable for us because the deeper perforation the lower skin factor. Figure 2 shows the relationship between the perforation depth and the flow rate. The flow rate increased with the increasing of the perforation depth.

$$
\begin{aligned}
& \mathrm{S}_{\mathrm{a}}=(169 / 33.8-1) \ln (1.375 / 0.292) \\
& \mathrm{S}_{\mathrm{a}}=7.98
\end{aligned}
$$

Table 19 The Calculation of the Skin Factor (S) for Well I

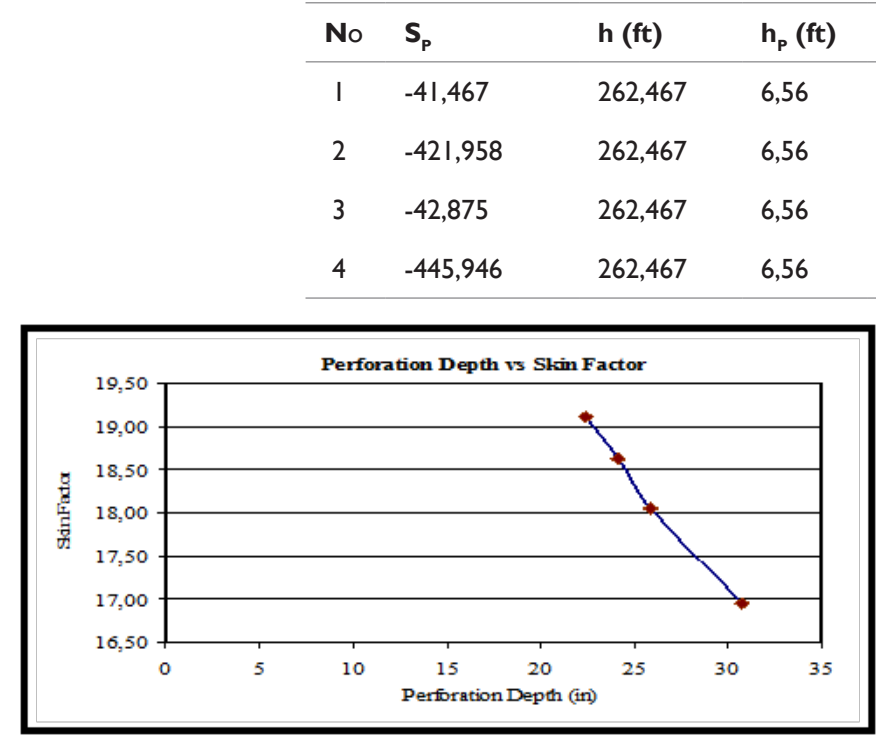

Figure I The Relationship between Perforation Depth and Skin Factor for Well.

\section{Calculate the flow rate $q_{o}$ (bbl/day)}

We used the equation (1) to calculate the flow rate considering the total skin factor that we calculated in the step 4, thus the data from the Table 4. I released that the lower skin factor (S) the higher flow rate $\left(\mathrm{q}_{\mathrm{o}}\right)$ as you can see in the Table 20 as well as Figure 3. As well you can see the best type of gun to have the higher productivity is the gun 4 , with deeper perforation depth. The Figure 3 shows the relationship between the skin factor and the flow rate, as you can see increasing of skin factor decreasing of the flow rate.

Table 20 The Calculation Results of the Flow Rate $q_{\circ}$ (bbl/day) for Well I

\begin{tabular}{llll}
\hline No & $\mathbf{L}_{\mathbf{p}}$ (in) & $\mathbf{S}$ & $\mathbf{q}_{\mathbf{o}}$ \\
\hline Gun I & 22.4247 & 19.11743 & 179.3193 \\
Gun2 & 24.14187 & 18.62041 & 182.547 \\
Gun3 & 25.85903 & 18.05387 & 186.3709 \\
Gun4 & 30.76522 & 16.94516 & 194.3376
\end{tabular}

$\begin{array}{llll}\mathbf{h} / \mathbf{h}_{\mathbf{p}} & \mathbf{S}_{\mathbf{a}} & \mathbf{S}_{\mathrm{dp}} & \mathbf{S} \\ 4,001,02 \mathrm{I} & 7,98 & 3,766,428 & \mathrm{I}, 91 \mathrm{I}, 743 \\ 4,001,021 & 7,98 & 356,099 & \mathrm{I}, 862,04 \mathrm{I} \\ 4,001,021 & 7,98 & 3,266,209 & 1,805,387 \\ 4,001,021 & 7,98 & 2,845,485 & 1,694,516\end{array}$

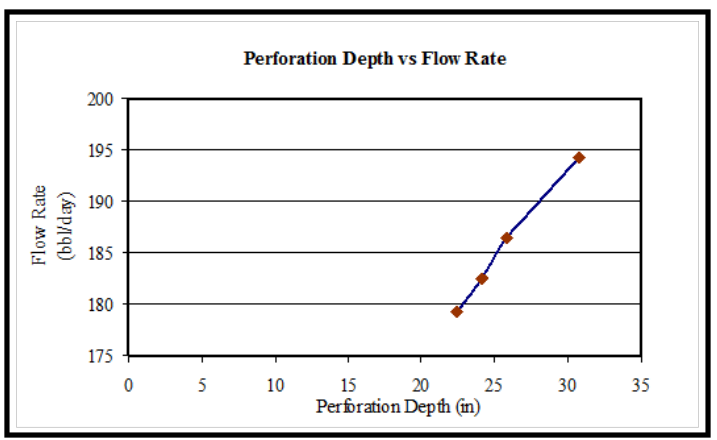

Figure 2 The Relationship between Perforation Depth and Flow Rate for Well I.

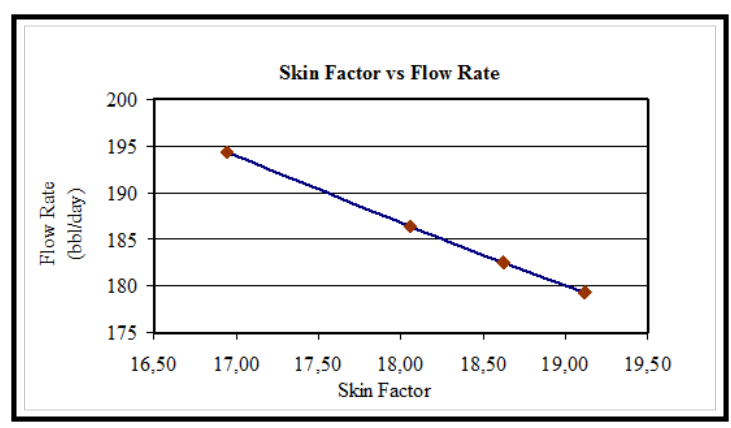

Figure 3 The Relationship between Skin Factor and Flow Rate for Well I.

\section{Calculate the flow rate of the other wells}

We followed the steps that we used to calculate the different parameters in the well 1 to determine the skin factor and flow rate of all the other wells. 
For well 2: Our work in well 2, considering the parameters in the Table 21-23. The final result that we got in the Table 23 is the flow rate of the well 2 by using different kind of guns. As you can see in our work the best flow rate was at using the gun 4 , herein in this well we retested that the flow rate quiet low because of the interval perforation was so small. In this case, we recommended to perforate with high

Table 2I The Calculation Results for the Perforation Depth for Well 2 interval perforation length to get more increasing flow rate. As you can see, Figure 4 shows the relationship between the perforation depth and the skin factor, and Figure 5 shows the relationship between the perforation depth and the flow rate. Figure 6 shows the relationship between the skin factor and the flow rate.

\begin{tabular}{llllll}
\hline Number of gun & Phasing & Shots (Spf) & Compressive & Total target penetration(In) & Perforation depth \\
& $\left(^{\circ}\right)$ & & strength ( Pisa) & ( In ) \\
\hline 1 & 60 & 6 & 4094.174 & 19.2 & 22.48833 \\
2 & 60 & 6 & 4094.174 & 20.6 & 24.21013 \\
3 & 60 & 6 & 4094.174 & 22 & 25.93194 \\
4 & 60 & 6 & 4094.174 & 26 & 30.85138 \\
\hline
\end{tabular}

Table 22 The Calculation Results for the Skin Factor (S) for Well 2

\begin{tabular}{llllllll}
\hline No & $\mathbf{S}_{\mathbf{p}}$ & $\mathbf{h}(\mathbf{f t})$ & $\mathbf{h}_{\mathbf{p}}(\mathbf{f t})$ & $\mathbf{h} / \mathbf{h}_{\mathbf{p}}$ & $\mathbf{S}_{\mathbf{a}}$ & $\mathbf{S}_{\mathrm{dp}}$ & $\mathbf{S}$ \\
\hline $\mathrm{I}$ & -4.1495 & 19.685 & 3.28 & 6.001524 & 7.93 & 5.017458 & 27.72193 \\
2 & -4.22237 & 19.685 & 3.28 & 6.001524 & 7.93 & 4.660621 & 26.92777 \\
3 & -4.29029 & 19.685 & 3.28 & 6.001524 & 7.93 & $4.35 \mathrm{E}+00$ & 26.21071 \\
4 & -4.46223 & 19.685 & 3.28 & 6.001524 & 7.93 & $3.66 \mathrm{E}+00$ & 24.48499 \\
\hline
\end{tabular}

Table 23 The Calculation Results for the Flow Rate $q_{o}$ (bbl/day) for Well 2

\begin{tabular}{clll}
\hline No & $\mathbf{L}_{\mathbf{p}}$ (in) & $\mathbf{S}$ & $\mathrm{q}_{\mathrm{o}}$ (bbl/day) \\
\hline $\mathrm{I}$ & 22.48833 & 27.72193 & 24.56318 \\
2 & 24.21013 & 26.92777 & 25.10833 \\
3 & 25.93194 & 26.21071 & 25.62176 \\
4 & 30.85138 & 24.48499 & 26.94794 \\
\hline
\end{tabular}

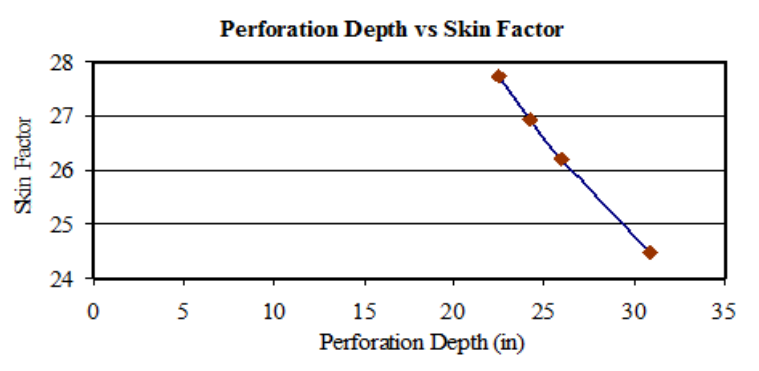

Figure 4 The Relationship between Perforation Depth and Skin Factor for Well 2.

For well 3: Our work in well 3, considering the parameters in the Table 24-26. Table 24 shows the results of our calculation of the different parameters of the well 3 by using the same steps in the well 1. As you can see the final results was the calculation of the flow rate. Figure 7 shows the relationship between the perforation depth and the skin factor and Figure 8 shows the relationship between the perforation depth and the flow rate. Figure 9 shows the relationship between the skin factor and the flow rate

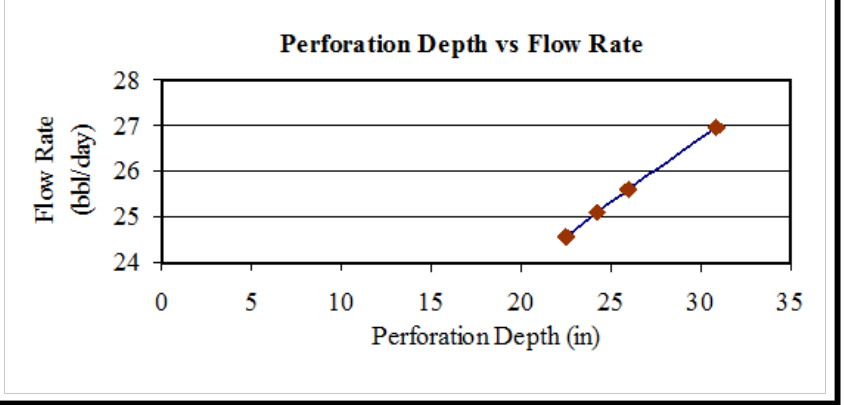

Figure 5 The Relationship between Perforation Depth and Flow Rate for Well 2.

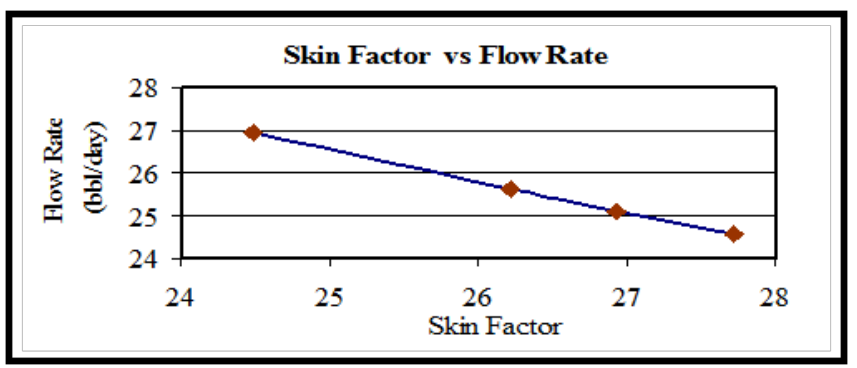

Figure 6 The Relationship between Skin Factor and Flow Rate for Well 2.

For well 4: Our work in well 4, considering the parameters in the Table 27-29. Table 29 shows the final result of our calculation of well 4 , in our work of this well, we released that the influence of the skin factor not too much because the influence of the oil permeability more than the skin factor the permeability is high in this well. As you can see, Figure 10 shows the relationship between the perforation depth 
and the skin factor and Figure 11 shows the relationship between the perforation depth and the flow rate. Figure 12 shows the relationship between the skin factor and the flow rate. After our calculation of the well 2 and well 3 and well 4 by using the same steps that we did in well 1 , we determine the influence of perforation depth and the skin factor with the flow rate. Thus the best gun that we recommended is by using gun 4 . If we used gun 4 for these wells we will increased the oil production will higher penetration into the formation zone.

Table 24 The Calculation Results for the Perforation Depth for Well 3

\begin{tabular}{|c|c|c|c|c|c|}
\hline Gun number & $\begin{array}{l}\text { Phasing } \\
\left({ }^{\circ}\right)\end{array}$ & Shots (spf) & $\begin{array}{l}\text { Compressive } \\
\text { strength (Pisa) }\end{array}$ & Total target penetration (in) & $\begin{array}{l}\text { Perforation depth } \\
\text { (in) }\end{array}$ \\
\hline I & 60 & 6 & 4217.39 & 19.2 & 22.23943 \\
\hline 2 & 60 & 6 & 4217.39 & 20.6 & 23.94309 \\
\hline 3 & 60 & 6 & 4217.39 & 22 & 25.64674 \\
\hline 4 & 60 & 6 & 4217.39 & 26 & 30.51433 \\
\hline
\end{tabular}

Table 25 The Calculation Results for the Skin Factor (S) for Well 3

\begin{tabular}{llllllll}
\hline No & $\mathbf{S}_{\mathbf{p}}$ & $\mathbf{h}(\mathbf{f t})$ & $\mathbf{h}_{\mathbf{p}}(\mathbf{f t})$ & $\mathbf{h} / \mathbf{h}_{\mathbf{p}}$ & $\mathbf{S}_{\mathbf{a}}$ & $\mathbf{S}_{\mathrm{dp}}$ & $\mathbf{S}$ \\
\hline $\mathrm{I}$ & -4.13851 & 4.9213 & 4.92 & 1.000264 & 7.91 & 5.749455 & 9.521972 \\
2 & -4.21141 & 4.9213 & 4.92 & 1.000264 & 7.91 & 5.340356 & 9.039958 \\
3 & -4.27935 & 4.9213 & 4.92 & 1.000264 & 7.91 & 4.985608 & 8.617251 \\
4 & -4.45134 & 4.9213 & 4.92 & 1.000264 & 7.91 & 4.190313 & 7.649917 \\
\hline
\end{tabular}

Table 26 The Calculation Results for the Flow Rate qo (bbl/day) for Well 3

\begin{tabular}{llll}
\hline No & LP (in) & S & $\mathbf{q}_{\mathrm{o}}(\mathbf{b b l} /$ day $)$ \\
\hline $\mathrm{I}$ & 22.23943 & 9.521972 & 52.55092 \\
2 & 23.94309 & 9.039958 & 53.961 \\
3 & 25.64674 & $8.61725 \mathrm{I}$ & 55.26137 \\
4 & 30.51433 & 7.649917 & 58.48674 \\
\hline
\end{tabular}

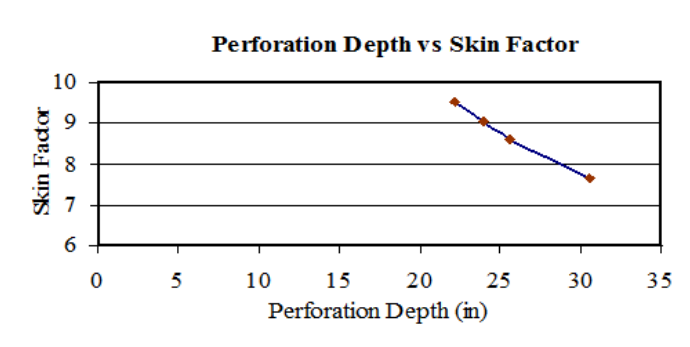

Figure 7 The Relationship between Perforation Depth and Skin Factor for Well 3.

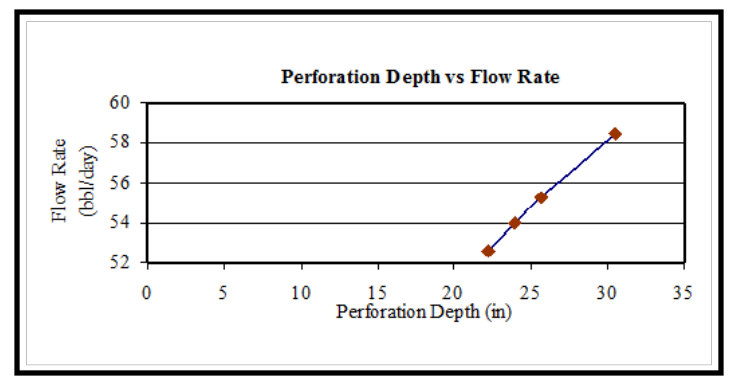

Figure 8 The Relationship between Perforation Depth and Flow Rate for Well 3.

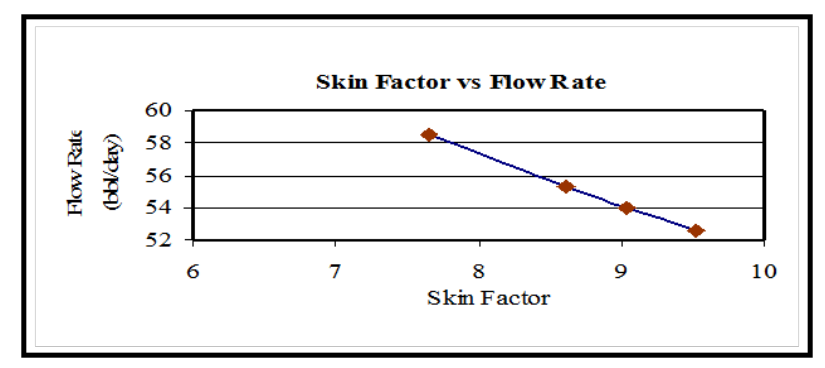

Figure 9 The Relationship between Skin Factor and Flow Rate for Well 3.

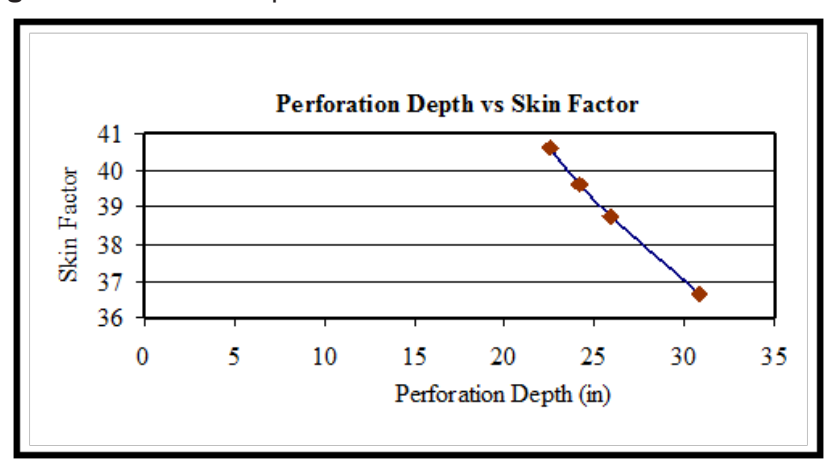

Figure 10 The Relationship between Perforation Depth and Skin Factor for Well 4.

\section{Evaluation of different guns and influence of it}

The aim was to compeering the effect of the guns for the flow rate of each well. We made relationship between the flow rate and perforation depth with different kind of guns, and we found the influence of the effected guns with the perforation depth of all oil vertical wells. This relationship was shown in the Figure 13-16. Table 30-33 and figures 13 through 16 show the effect of gun $1,2,3$, and 4 with different oil vertical wells. Highest flow rate that we can see was in the well 4 and the lowest flow rate was in well 2. 


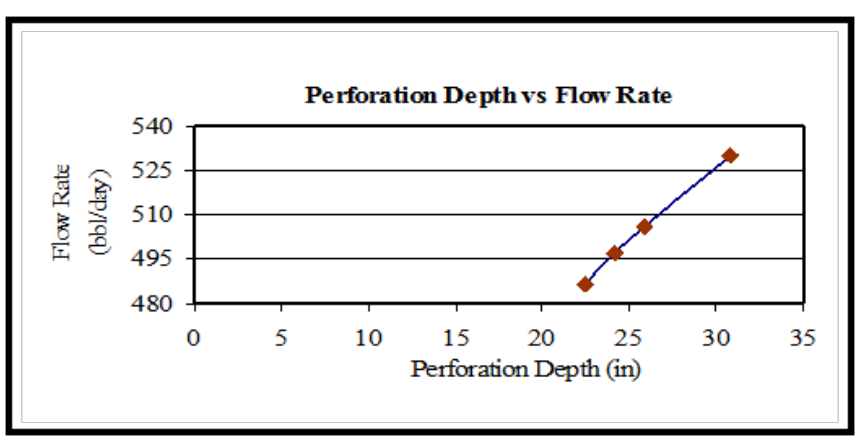

Figure II The Relationship between Perforation Depth and Flow Rate for Well 4.

Table 27 The Calculation Results for the Perforation Depth for Well 4

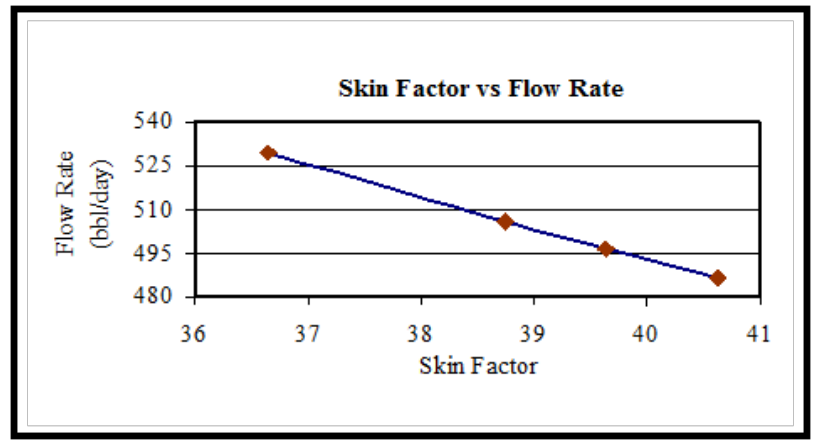

Figure 12 The Relationship between Skin Factor and Flow Rate for Well 4.

\begin{tabular}{llllll}
\hline Gun number & $\begin{array}{l}\text { Phasing } \\
\left({ }^{\circ}\right)\end{array}$ & Shots (Spf) & $\begin{array}{l}\text { Compressive } \\
\text { strength (Pisa) }\end{array}$ & Total target penetration (In) & $\begin{array}{l}\text { Perforation depth } \\
\text { (In) }\end{array}$ \\
\hline 1 & 60 & 6 & 4101.885 & 19.2 & 22.47267 \\
2 & 60 & 6 & 4101.885 & 20.6 & 24.19334 \\
3 & 60 & 6 & 4101.885 & 22 & 25.914 \\
4 & 60 & 6 & 4101.885 & 26 & 30.83018 \\
\hline
\end{tabular}

Table 28 The Calculation Results for the Skin Factor (S) for Well 4

\begin{tabular}{llllllll}
\hline No & $\mathbf{S P}$ & $\mathbf{h}(\mathbf{f t})$ & $\mathbf{h}_{\mathbf{p}}(\mathbf{f t})$ & $\mathbf{h} / \mathbf{h}_{\mathbf{P}}$ & $\mathbf{S}_{\mathbf{a}}$ & $\mathbf{S}_{\mathrm{dp}}$ & $\mathbf{S}$ \\
\hline $\mathrm{I}$ & -4.58986 & 193.59 & 32.8 & 5.902134 & 10.14 & 7.835891 & 40.61719 \\
2 & -4.66306 & 193.59 & 32.8 & 5.902134 & 10.14 & 7.278592 & 39.6279 \\
3 & -4.73126 & 193.59 & 32.8 & 5.902134 & 10.14 & 6.795301 & 38.74208 \\
4 & -4.90383 & 193.59 & 32.8 & 5.902134 & 10.14 & 5.711722 & 36.63994 \\
\hline
\end{tabular}

Table 29 The Calculation Results for the Flow Rate qo (bbl/day) for Well 4

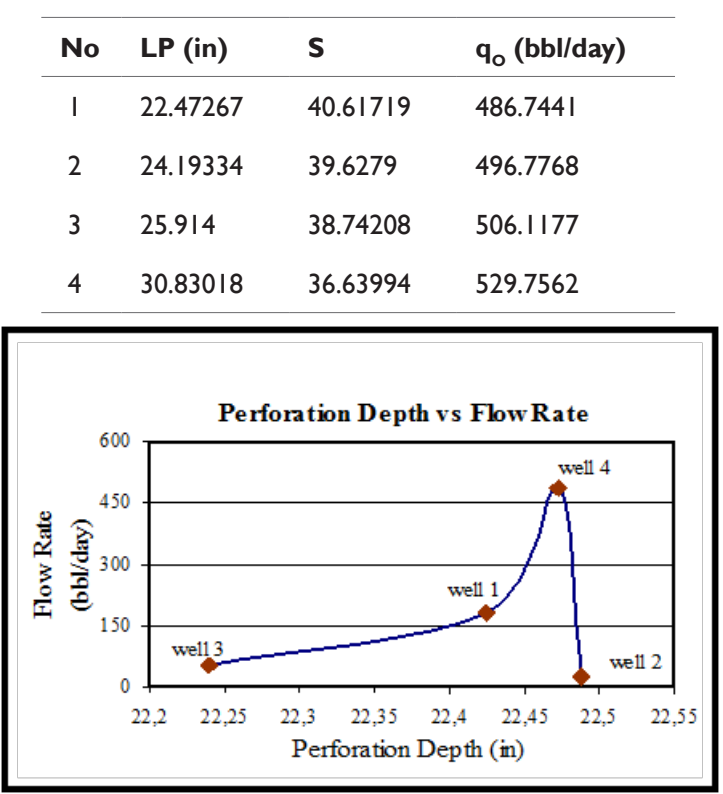

Figure 13 The Relationship between Perforation Depth and Flow Rate for Gunl.

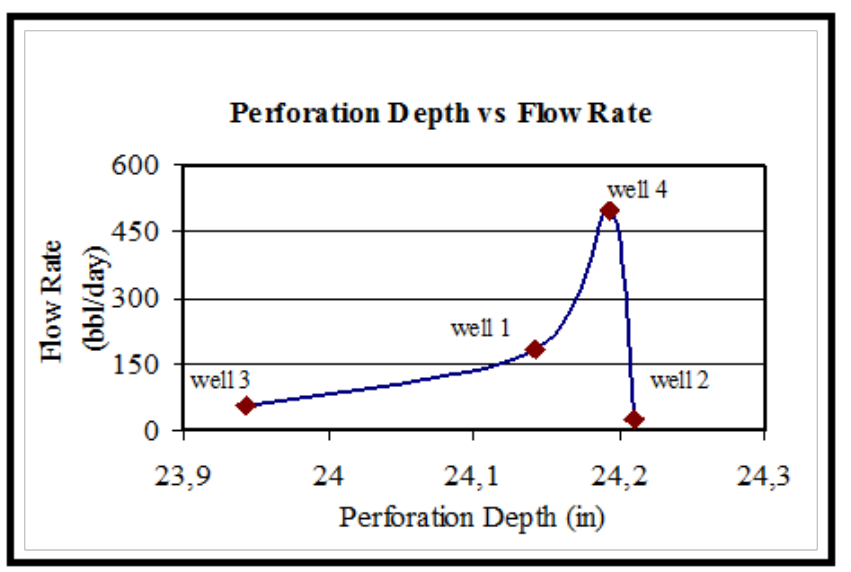

Figure 14 The Relationship between Perforation Depth and Flow Rate for Gun2.

\section{Comparing between the different high shot density Guns}

Comparing between the results of the flow rate and perforation depth by using different high shot density Guns. Figure 17 shows the comparing of the flow rate with different kind of guns. The higher 
flow rate we can have with selecting the gun 4 with higher perforation depth, the lower flow rate we can see with choosing the gun 1 with lower perforation depth. The main conclusion belonging to the Figure 17 , each gun gives the highest flow rate at well 4 , but comparing the effect of the guns as you can see, this is dependent on the perforation depth and the compressive strength of the layers because the well test shows well 4 has the highest interval perforation of two sections. The deeper perforation that we got by using gun 4 with highest API RP 43 penetrations, that we got from the Schlumberger engineered perforation systems. The flow rate as you can see in the Figure 17 is slightly increasing of all the guns. We consider the damage zone thickness of all the wells are the same, if it not the same property will shot through the damage zone might be different by using the different kind of high shot density guns.

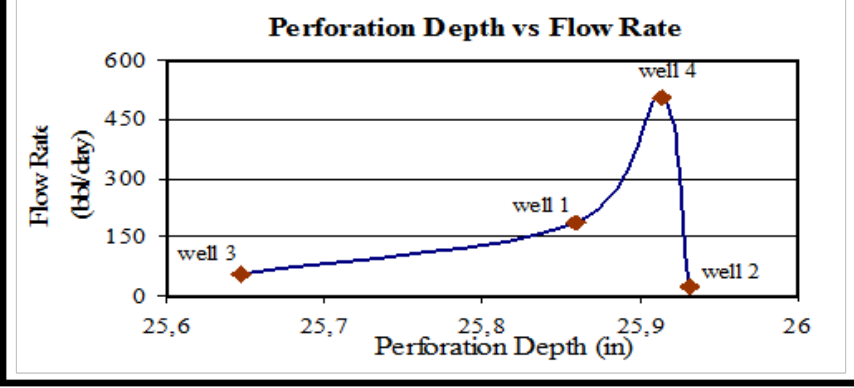

Figure I 5 The Relationship between Perforation Depth and Flow Rate for Gun3.

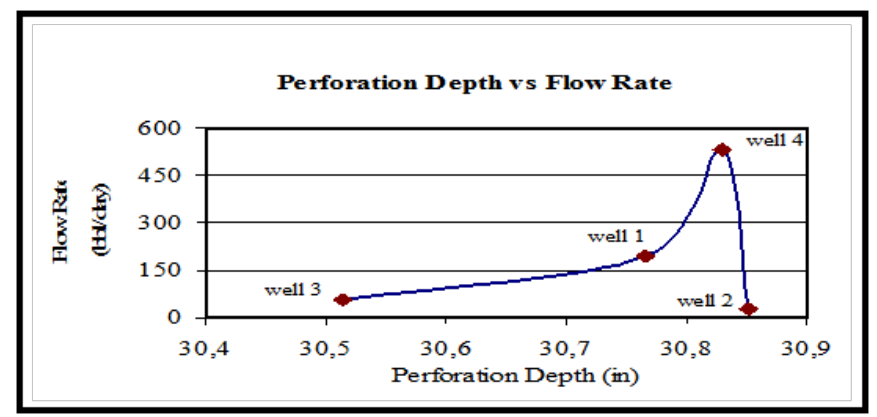

Figure 16 The Relationship between Perforation Depth and Flow Rate for Gun3.

Table 30 The Calculation Results for the Flow Rate $q_{o}(b b l / d a y)$ for Gun I

\begin{tabular}{llll}
\hline No & $\mathbf{L}_{\mathbf{p}}$ (in) & $\mathbf{S}$ & $\mathbf{q}_{\mathrm{o}}$ (bbl/day) \\
\hline 3 & 25.64674 & $8.61725 I$ & 55.26137 \\
$\mathrm{I}$ & 25.85903 & 18.05387 & 186.3709 \\
4 & 25.914 & 38.74208 & 506.1177 \\
2 & 25.93194 & $26.2107 \mid$ & 25.62176
\end{tabular}

Table 31 The Calculation Results for the Flow Rate $\mathrm{q}_{\mathrm{o}}$ (bbl/day) for Gun2

\begin{tabular}{llll}
\hline No & $\mathbf{L}_{\mathbf{p}}$ (in) & $\mathbf{S}$ & $\mathbf{q}_{\mathrm{o}}(\mathbf{b b l} /$ day $)$ \\
\hline Well 3 & 23.94309 & 9.039958 & 53.961 \\
Well I & 24.14187 & 18.62041 & 182.547 \\
Well 4 & 24.19334 & 39.6279 & 496.7768 \\
Well 2 & 24.21013 & 26.92777 & 25.10832 \\
\hline
\end{tabular}

Table 32 The Calculation Results for the Flow Rate q。 (bbl/day) for Gun3

\begin{tabular}{llll}
\hline No & $\mathbf{L}_{\mathbf{p}}$ (in) & $\mathbf{S}$ & $\mathbf{q}_{\mathrm{o}}$ (bbl/day) \\
\hline Well 3 & 22.23943 & 9.521972 & 52.55092 \\
Well I & 22.4247 & 19.11743 & 179.3193 \\
Well 4 & 22.47267 & 40.61719 & $486.744 \mid$ \\
Well 2 & 22.48833 & 27.72193 & 24.56318
\end{tabular}

Table 33 The Calculation Results for the Flow Rate $q_{\circ}$ (bbl/day) for Gun4

\begin{tabular}{llll}
\hline No & $\mathbf{L}_{\mathbf{p}}$ (in) & $\mathbf{S}$ & $\mathbf{q}_{\mathbf{o}}$ (bbl/day) \\
\hline 3 & 30.51433 & 7.649917 & 58.48674 \\
1 & 30.76522 & 16.94516 & 194.3375 \\
4 & 30.83018 & 36.63994 & 529.7562 \\
2 & 30.85138 & 24.48499 & 26.94794 \\
\hline
\end{tabular}

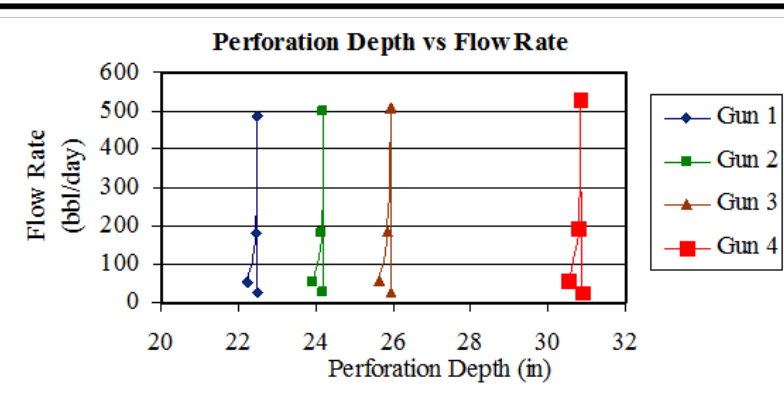

Figure 17 The Comparison between Flow Rate Results While Using Different Kind of High Shot Density (HSD) Guns.

\section{Conclusion}

The first conclusion as we prove in this work that there is a calculation method by which the flow rate of the vertical oil wells can be estimated before perforating. To have the best flow rate the right design of the guns we should choose. The most important parameters influence the productivity of the perforated oil vertical wells are (penetration depth, perforation diameter, shot density, and phasing angular). In this work we evaluate the productivity of four selected wells in Hungary field, the main results of our evaluation are listed below:-

a. The perforation depth based on the compressive strength of the layer (the higher compressive strength the lower perforation depth).

b. The perforation skin factor based on different skin effect like (flow pseudoskin factor, vertical pseoduskin factor, wellbore skin factor).

c. The crushed zone skin factor based on (formation permeability, crushed zone permeability, damage zone permeability, perforation interval, perforation radius, crushed zone radius, perforation depth).

d. The skin factor based on (crushed zone skin factor, perforation skin factor, damage zone skin factor, perforation interval).

e. The flow rate based on the total skin factor and other parameters like (reservoir properties, flow properties, well radius, Drainage radius). 
The longer perforation interval the higher flow rate that can be obtained. In this work we couldn't use the rearranged Harris handy charts by standing for calculation of the perforation skin factor because it is not including the all phasing angle and the shot density. In this work we used high shot density guns with phasing angle $\left(60^{\circ}\right)$ and we got a good result by using some MOL company data. Depending on our results, we recommend using these guns to have higher flow rates. Finally this kind of Hungarian wells would give the highest production rate if it perforated with high shut density guns, the best results if these wells perforated with gun 4 .

\section{Acknowledgements}

None.

\section{Conflict of interest}

The authors declare no conflict of interest.

\section{References}

1. Hurst W. Establishment of the Skin Effect and Its Impediment to Fluid into a Well Bore. Pet Eng. B6-B16. 1953.

2. Van Everdingen AF. The Skin Effect and Its Influence on the Productive Capacity of a Well. Trans AIME. 1953;5(6):171-176.

3. Muskat M. The Flow of Homogeneous Fluids Through Porous Media International Human Resources Development Corporation. USA, 1937.

4. Muskat M. The Effect of Casing Perforations on Well Productivity. Trans AIME. 1943;151(1):175-187.
5. McDowell IM, Muskat M. The Effect on Well Productivity of Formation Penetration beyond Perforated Casing. Trans AIME. 1950;2(11):309323.

6. Howard RA, Watson MS. Relative Productivity of Perforated Casing-1. Trans AIME. 1950;2(6):1-4.

7. Harris MN. The Effect of Perforating on Well Productivity. Trans AIME. 1966;18(4):1-11.

8. Hong KC. Productivity of Perforated Completions in Formations With or Without Damage. J Pet Tech. 1975;27(8):1027-1038.

9. Locke S. An Advanced Method for Predicting the Productivity Ratio of a Perforated Well. J Pet Tech. 1981;33(12):2481-2488.

10. Standing MB. Reservoirs, course Manual in Reservoir Engineering Continental Shelf Development. Norway: Petroleum Industry Courses. NTH Trondheim; 1980.

11. Craft BC, Hawkins MF. Applied Petroleum Reservoir Engineering. USA: Prentice-Hall Book Co, Englewood Cliffs; 1959.

12. Thompson GD. Effects of Formation Compressive Strength on Perforator Performance. USA: Drill and Prod Prac; 1962.

13. McLeod HO. The Effect of Perforating Conditions on Well Performance. J Pet Tech. 1983;35(1):31-39.

14. Rowland DA. Pressure Buildup and Drawdown Behavior in under saturated Reservoirs of Discontinuous Permeability. USA: Stanford University; 1969.

15. Jones LG, Watts JW. Estimating Skin Effect in a Partially Completed Damaged Well. J Pet Tech. 1971;23(2):249-252. 